\title{
La mobilité des migrants d'Ouzbékistan : transport, frontières et circulation migratoire
}

Uzbekistan Migrants Movement: Transportation, Borders and Migratory

Circulation

La movilidad de los emigrantes de Uzbekistán: transportes, fronteras y

circulación migratoria

\section{Julien Thorez}

\section{(Q) OpenEdition}

\section{Journals}

Édition électronique

URL : https://journals.openedition.org/remi/5207

DOI : $10.4000 /$ remi.5207

ISSN : $1777-5418$

Éditeur

Université de Poitiers

Édition imprimée

Date de publication : 1 décembre 2010

Pagination : $31-57$

ISBN : 978-2-911627-56-9

ISSN : 0765-0752

Référence électronique

Julien Thorez, «La mobilité des migrants d'Ouzbékistan : transport, frontières et circulation

migratoire ", Revue européenne des migrations internationales [En ligne], vol. $26-n^{\circ} 3 \mid 2010$, mis en ligne le 01 décembre 2013, consulté le 14 avril 2022. URL : http://journals.openedition.org/remi/5207 ; DOI : https://doi.org/10.4000/remi.5207 


\section{La mobilité des migrants d'Ouzbékistan : transport, frontières et circulation migratoire}

\section{Julien THOREZ ${ }^{1}$}

Dlusieurs vagues migratoires se sont succédé depuis la seconde moitié des années 1980 pour faire de l'Ouzbékistan un pays d'émigration². La fin de la période soviétique a vu l'intensification et l'internationalisation des flux migratoires parmi les populations " russophones $»^{3}$, suite à la décision des autorités soviétiques d'assouplir les conditions d'émigration en 1987 (de Tinguy, 2004 ; Korobkov et Zaïonchovskaia, 2004) ${ }^{4}$. Commun à tous les pays d'Asie centrale et du Caucase, ce processus a pris en Ouzbékistan une résonance particulière après les violences interethniques dont furent victimes les Meskhètes dans le Ferghana en 1989. Plusieurs centaines de milliers de Russes, de Tatars, d'Ukrainiens, d'Allemands, de Juifs ou de Grecs ont depuis définitivement quitté l'Ouzbékistan indépendant tandis que les populations " centre-asiatiques » (Ouzbeks, Tadjiks, Karakalpaks) demeuraient à l'écart de ce flux qui a fondamentalement transformé la société ouzbékistanaise (Maksakova, 2009).

1 Géographe, Chargé de recherche au CNRS, Mondes iranien et indien, 27, rue Paul Bert, 94204 Ivry-sur-Seine ; julienthorez@hotmail.com

2 Cet article a été rédigé dans le cadre du programme « Le Caucase et l'Asie centrale : un autre sud?», financé par l'ANR (2008-2012).

3 Cette catégorie désigne les populations arrivées en Asie centrale de façon volontaire, encadrée ou forcée, durant les périodes tsaristes et soviétiques (Laitin, 1998 ; Thorez, 2009).

4 Les flux d'immigration se sont presque taris durant les années 1990 d'autant que, contrairement au Kazakhstan et au Kirghizstan, l'Ouzbékistan n'a pas mis en œuvre de politique de « rapatriement » des minorités co-ethniques de l'étranger, pourtant nombreuses au Tadjikistan, au Kirghizstan, au Kazakhstan, au Turkménistan ou en Afghanistan (Ferrando, 2010).

5 Héritage des politiques tsariste et soviétique, une distinction est toujours opérée en Ouzbékistan entre la citoyenneté - ouzbékistanaise - qui renvoie à une identité civique, et la nationalité ouzbèke, tadjike, russe, etc. - qui correspond à une identité ethnique. 
Depuis la fin des années 1990, le développement des migrations de travail, dont les populations centre-asiatiques sont les principaux acteurs, produit une seconde vague d'émigration. L'émergence de ces flux saisonniers et temporaires s'est déroulée dans un contexte de crise de la mobilité et du système de transport - proche d'un million de passagers en 1990, le trafic de l'aéroport de Samarkand a été inférieur à 100000 passagers en 1995 (Thorez, 2005) - qui invite à questionner les fondements de la dynamique migratoire ainsi que les modalités de circulation des travailleurs-migrants. D'autant que cette mise en mouvement contraste avec l'atonie migratoire qui caractérisait les populations des qishloq (village) et des mahalla (communauté territorialisée correspondant à un quartier, conjuguant liens de voisinage et de parenté) durant la période soviétique. La généralisation des migrations de main-d'œuvre façonne de nouvelles territorialités qui participent à la redéfinition du positionnement de l'Ouzbékistan dans l'espace mondialisé. Étendu de l'Asie de l'Est à l'Amérique du Nord, mais polarisé par la Russie, l'espace migratoire ouzbékistanais articule des dynamiques globales et des dynamiques postcoloniales, qui illustrent la complexité de la transformation post-soviétique.

\section{MIGRATIONS DE TRAVAIL : L'ÉMERGENCE DE NOUVELLES TERRITORIALITÉS}

\section{Un flux difficilement quantifiable}

Les migrations de travail ont pris de l'importance depuis le tournant des années 2000. Toutefois, aucune source ne donne d'informations permettant de définir avec précision l'ampleur de ce processus. Les données communiquées par les institutions de l'État ouzbékistanais $^{6}$ tendent à minimiser un phénomène qui peut être interprété comme une manifestation de la dégradation de la situation économique et sociale survenue au cours de la période contemporaine (Laruelle, 2010a) ${ }^{7}$. Dans les pays de destination des travailleurs ouzbékistanais, les administrations ne recensent officiellement que les migrants disposant d'un permis de résidence ou de travail. Experts, chercheurs, associations et organisations non gouvernementales proposent des estimations du nombre de migrants plus élevées que les statistiques officielles : elles oscillent entre 2 et 8 millions de migrants. Ces évaluations témoignent de l'investissement de la société dans le processus d'externalisation de la main-d'œuvre et d'extraversion de l'accumulation du capital. Mais l'analyse des équilibres démographiques invite à considérer qu'environ 2 à 3 millions d'Ouzbékistanais travaillent saisonnièrement ou temporairement à l'étranger. Quoi qu'il en soit, l'Ouzbékistan est devenu le premier pays d'origine des Gastarbeiter employés en Russie, en fournissant environ $25 \%$ de la main-d'œuvre immigrée en 2008, de même qu'au Kazakhstan (Zajončkovskaâ, Mkrčân et Tûrûkanova, 2009 ; Sadovskaâ, 2009).

6 D'après l'Agence pour les migrations internationales de main-d'œuvre, créée en 2001 au sein du ministère du Travail et de la Sécurité sociale, seulement 262900 Ouzbékistanais travaillaient à l'étranger en 2005 (Maksakova, 2009).

7 Massot estime même que «migrer peut être considéré comme une prise de position politique, un acte militant » (2009). 


\section{Migrer, une pratique post-soviétique?}

\section{Une activité migratoire réduite}

L'ampleur des migrations contemporaines contraste avec l'enracinement des populations centre-asiatiques (Ouzbeks, Tadjiks, etc.) à la fin de la période soviétique. Au recensement de 1979, les Ouzbékistanais détenaient les taux de mobilité résidentielle les plus faibles de l'URSS (Maksakova, 1986) ${ }^{8}$. Aussi le peuplement ouzbek était-il caractérisé par un double ancrage, national et rural, quelquefois analysé comme l'expression d'une surpopulation corrélée à des formes de sous-développement (Patnaik, 1995). Pourtant, les autorités avaient tenté de stimuler les migrations à destination des régions soviétiques connaissant un déficit de main-d'œuvre (Sibérie, etc.) (Tarasova, 1985). À l'échelle de l'Ouzbékistan, elles avaient également agi sur la répartition de la population en organisant le peuplement de périmètres agricoles nouvellement mis en valeur dans la Steppe de la Faim et autour de Karchi, notamment depuis les oblast' du Ferghana (Maksakova, 2001). Cette politique volontariste visait à réduire les inégalités régionales du marché du travail et à contenir les tensions sociales dans les régions densément peuplées.

\section{L'atonie migratoire, une manifestation de sous-développement?}

Considérées dans le contexte ouzbékistanais des années 1970-1980 comme un levier de promotion sociale, les migrations avaient été auparavant contrôlées et limitées par l'État soviétique au moyen de dispositifs administratifs contraignants (permis de résidence [propiska], passeport intérieur, permis de travail, cf. Bater, 1989). Dissuasives, ces mesures communes à toutes les républiques soviétiques pouvaient apparaître comme une entrave à la mobilité, en particulier dans les campagnes. Toutefois, au moment où la population rurale s'enracinait en Ouzbékistan, plusieurs régions soviétiques connaissaient un intense exode rural et un processus de dépeuplement. En Russie, la population rurale s'est ainsi contractée de 72 à 39 millions d'habitants entre les recensements de 1939 et de 1989.

En Ouzbékistan, les réticences des populations centre-asiatiques à migrer dépendaient moins de la législation que de facteurs économiques, sociaux et culturels. La faible mobilité résidentielle s'inscrivait dans un contexte spécifique aux régions méridionales de l'Asie centrale marqué par l'organisation autocentrée des sociétés urbaines et rurales. D'une part, les familles turkestanaises, fondées sur une résidence patrilocale, exerçaient une attraction sur l'ensemble de leurs membres, d'autant plus forte que, dans les milieux ruraux, le niveau de vie était corrélé à la taille des familles (Zûzin, 1983 ; Mullâdžanov et Ubajdullaeva, 1988). D'autre part, l'inscription des individus dans le mahalla a longtemps favorisé l'enracinement des populations. Pour les populations centre-asiatiques, migrer impliquait en outre de s'éloigner voire de se couper de réseaux sociaux et familiaux dont le rôle était fondamental dans l'orientation des trajectoires individuelles et dans l'accès aux biens et aux services. De surcroît, quitter le village et/ou l'Ouzbékistan supposait de se confronter à un environnement russophone, souvent perçu comme étranger voire

$877 \%$ des habitants de la RSS d'Ouzbékistan ( $88 \%$ des ruraux) résidaient dans le même lieu depuis leur naissance. 
comme contradictoire avec les traditions nationales et religieuses associées aux mahalla et aux qishloq. Des frontières symboliques s'ajoutaient donc aux dispositifs législatifs pour limiter la mobilité résidentielle des Ouzbeks et des Tadjiks.

La spécialisation agricole des campagnes participait également de la faible demande migratoire. La production de coton, qui a connu un essor considérable dans le cadre du système soviétique de production et d'échanges, employait en effet une maind'œuvre abondante. Malgré l'importance du travail manuel, les campagnes connaissaient pourtant un sous-emploi chronique, partiellement compensé par l'emploi du surplus de main-d'œuvre dans les exploitations auxiliaires domestiques, i.e. dans l'agriculture privée (Patnaik, 1995). Cette situation aurait pu alimenter les flux d'émigration, mais les agriculteurs, dans l'ensemble mal formés, peinaient à se réorienter vers des métiers industriels ou tertiaires. De plus, ils devaient faire face à la concurrence d'une main-d'œuvre russophone qualifiée, dont la présence dans les villes a été analysée comme un obstacle aux migrations des campagnes vers les villes (Topilin, 1975).

Si les facteurs sociaux et culturels sont parfois présentés comme le fondement de l'atonie migratoire des Ouzbeks et des Tadjiks (Patnaik, 1995), les populations centreasiatiques semblaient également jouir d'un niveau de vie peu propice à la mobilité résidentielle. Dans les années 1980, les kolkhoziens et les sovkhoziens percevaient des rémunérations inférieures à la moyenne soviétique, mais les familles rurales bénéficiaient de la production et des revenus tirés de la vente des excédents des exploitations auxiliaires domestiques. Or, ces dernières avaient officiellement fourni la moitié des légumes, des fruits et de la viande ainsi que les deux tiers du lait produits en 1990. Issus de la vente directe, des achats de l'État et de l'écoulement des produits frais sur les bazars 9 , les revenus de l'agriculture privée représentaient de ce fait davantage que les rémunérations reçues par les agriculteurs dans les exploitations collectives (Tašbaeva et Suvurov, 1989). Alors que le coût de la vie était en Ouzbékistan inférieur à la moyenne soviétique (Zûzin, 1983), les activités non contrôlées par l'État augmentaient considérablement les ressources familiales et contribuaient par conséquent à limiter l'attraction des villes et des autres régions soviétiques. Dès lors, les politiques d'incitation à la mobilité conduites à la fin de la période soviétique furent sans grand effet. Au cours des années 1970-1980, 1'activité migratoire des populations russophones, dont le solde s'inversait pour devenir négatif, contrastait avec l'ancrage des populations centre-asiatiques - en 1980, les Ouzbeks représentaient $70 \%$ de la population, mais seulement $30 \%$ des migrants (Maksakova, 1986).

\section{Stabilité résidentielle et migrations professionnelles}

La stabilité résidentielle des populations centre-asiatiques des villes et des campagnes d'Ouzbékistan coexistait cependant avec différentes formes de mobilité professionnelle. À partir des années 1960, les migrations pendulaires ont connu un développement régulier autour des principales agglomérations, stimulé par l'industrialisation et la modernisation des moyens de transport (Maksakova, 1986). Dans la majorité des cas, les entreprises organisaient le transport des salariés par autocar, entre les villages périurbains et les usines (Aliakberova et al., 1990).

9 En 1985, $50 \%$ des légumes, $40 \%$ des fruits et $25 \%$ de la viande consommés par les ouvriers et les salariés d'Ouzbékistan ont été achetés sur les marchés paysans (Ivatov, 1994).

REMI 2010 (26) 3 pp. 31-57 
Parallèlement aux migrations pendulaires, des migrations saisonnières mobilisaient des travailleurs ouzbékistanais. En Ouzbékistan, des paysans se rendaient dans les régions méridionales (Surkhan-Daria, Kachka-Daria) pour participer à la culture du riz et de l'oignon (Maksakova, 2001). En septembre-octobre, plusieurs milliers de jeunes urbains, étudiants ou travailleurs mis à disposition par leurs autorités respectives, étaient affectés à la cueillette du coton. À l'échelle soviétique, les migrants saisonniers, en grande majorité des hommes travaillant en été comme ouvriers qualifiés sur des chantiers de construction, se dirigeaient vers la Russie et secondairement vers le Kazakhstan (Aliakberova et al., 1990 ; Maksakova, 2001). À côté de ces migrations planifiées, il existait également des formes de mobilité non encadrée. Durant l'été, des Ouzbékistanais partaient pour la Russie afin de vendre sur les marchés urbains les fruits et les légumes produits dans les oasis (Reeves, 2010). Organisés ou informels, ces différents flux s'inscrivaient dans un système de mobilité plus large, qui incluait notamment d'autres déplacements professionnels et des mobilités touristiques. En ce sens, l'ancrage résidentiel exceptionnel des Ouzbeks ne signifiait pas que la société était immobile, repliée ou isolée. Si la mobilité des Centreasiatiques était moindre que celle des populations exogènes, leur horizon géographique ne se bornait pas aux limites des qishloq et des mahalla ni aux frontières de l'Ouzbékistan. Toutefois, parmi les populations ouzbèkes, la mobilité des hommes différait de celle des femmes, les itinéraires de vie des premiers - soviétiques - contrastant avec les territorialités centre-asiatiques des secondes.

\section{Les déterminants de la mobilité : l'essor des migrations de travail}

La disparition de l'URSS, quelquefois présentée comme une date charnière dans l'histoire des migrations ouzbékistanaises (Massot, 2009), n'a pas coïncidé avec une modification immédiate des pratiques migratoires des Ouzbeks. Apparues à la fin des années 1990 et intenses depuis 2002-2003, les migrations de travail ne se sont développées en Ouzbékistan qu'après leur essor au Tadjikistan et au Kirghizstan (Brusina, 1998). Une approche économique des migrations indiquerait que la politique de réformes graduelles menée par l'Ouzbékistan a permis d'amortir la crise post-soviétique, en préservant quelque peu les salaires et les emplois, y compris dans les campagnes où, dans un premier temps, ont été maintenues des exploitations collectives (Abdullaev, 2008). La faiblesse du flux d'émigration aurait aussi été liée au développement de l'économie de marché et à l'apparition de nouvelles activités productives et commerciales, quelquefois informelles, qui ont fourni du travail et assuré un revenu à une part importante de la population, notamment sur les bazars. Au cours des années 1990, la situation économique dégradée limitait enfin les besoins en main-d'œuvre de la Russie et du Kazakhstan, qui connaissaient pourtant une crise démographique.

\section{Pression démographique et mutations économiques : au cœur de la demande migratoire}

Si l'essor des migrations de travail fut postérieur à la crise post-soviétique, l'émergence des nouvelles pratiques migratoires renvoie fondamentalement à la situation économique et sociale, en dépit de la complexité des mécanismes qui structurent la demande de mobilité. En Ouzbékistan, l'extraversion de la main-d'œuvre traduit avant tout la mise 
en œuvre de stratégies individuelles et familiales destinées à s'affranchir des difficultés économiques. Malgré la croissance enregistrée depuis la seconde moitié des années 1990, les revenus restent modestes, notamment dans les campagnes ${ }^{10}$. Phénomène classique, les plus pauvres ne peuvent mobiliser les ressources nécessaires pour migrer, mais la majorité de la population vit dans un entre-deux économique insatisfaisant, mais suffisant pour financer des projets migratoires, alors même que le marché du travail connaît des tensions liées à la rapide croissance démographique (Tableau 1). Les années 2000 correspondent en effet à l'entrée sur le marché du travail des générations nombreuses nées au cours du pic de natalité des années 1980. De ce fait, malgré la croissance économique, la création de nouveaux postes dans les secteurs public et privé ne répond que partiellement à l'augmentation de la population active ${ }^{11}$. Les migrations de travail contribuent alors à pallier l'insuffisance des revenus et à atténuer la pénurie d'emplois. Pour l'État, cette mobilité internationale saisonnière et temporaire permet de réguler un marché du travail, dont elle est désormais un segment essentiel (Maksakova, 2009).

Tableau 1 : La croissance démographique de l'Ouzbékistan (1991-2006)

\begin{tabular}{|l|c|c|c|}
\hline & 1991 & 2000 & 2006 \\
\hline Population totale (M) & 20,857 & 24,650 & 26,488 \\
\hline $\begin{array}{l}\text { Population en âge de } \\
\text { travailler (M) }\end{array}$ & 10,213 & 12,469 & 14,816 \\
\hline Population active (M) & 8,383 & 9,018 & 10,492 \\
\hline
\end{tabular}

Source : Comité des statistiques de l’Ouzbékistan

Dans les campagnes, l'accroissement des migrations de main-d'œuvre coïncide également avec l'accélération de la réforme agraire. Le démantèlement des exploitations collectives au profit d'une agriculture paysanne a participé à la mise en migration de la société rurale. En rupture avec les pratiques territoriales traditionnelles, plusieurs centaines de milliers de ruraux ont connu leur première expérience migratoire depuis le début des années 2000. Qu'elles soient internationales (saisonnières ou temporaires) ou nationales (pendulaires ou saisonnières), ces migrations concourent à la " prolétarisation » des campagnes - toujours très agricoles - de l'Ouzbékistan (Bazin, 2009). Dans le pays de villages qu'est l'Ouzbékistan, cette mobilité internationale s'apparente aussi à une forme classique d'externalisation de l'exode rural. Toutefois la généralisation des migrations depuis les campagnes vers l'étranger et vers les villes s'opère dans un contexte économique et technique spécifique où l'agriculture ne connaît pas d'élévation du niveau de mécanisation ni de croissance significative de la production.

10 Le salaire mensuel « réel » serait de quarante à cinquante dollars.

11 La part des « ressources laborieuses » [trudovye resursy] s'est élevée de $49 \%$ en 1989, à $52 \%$ en 2000 puis à $59,5 \%$ de la population ouzbékistanaise en 2008 . 


\section{De la circulation commerciale à la mobilité migratoire : exploiter les diffé- rentiels frontaliers}

L'internationalisation des migrations de main-d'œuvre a aussi succédé à la redéfinition des conditions de résidence et de travail impulsée par l'État, au tournant des années 2000. À la suite d'attentats perpétrés à Tachkent en février 1999 et attribués par le pouvoir à des mouvements islamistes radicaux, le gouvernement a pris la décision de renforcer les mesures de sécurité et d'exercer des contrôles accrus sur la population (Trudovye..., 2005). Alors que le système du permis de résidence existe toujours, ces mesures ont surtout affecté les habitants permanents ou temporaires de Tachkent n'ayant pas d'enregistrement dans la capitale, c'est-à-dire les migrants. Parmi ces derniers, les hommes, d'une part, et les migrants originaires du Ferghana, région dont les principaux dirigeants du Mouvement Islamique d'Ouzbékistan étaient issus, d'autre part, furent particulièrement ciblés. Cette politique sécuritaire a contraint les migrants à modifier leurs pratiques territoriales. En premier lieu, elle a favorisé la féminisation des migrations intérieures, les femmes étant moins soumises à la pression policière (Artykova, 2007). En second lieu, elle a incité des migrants du Ferghana à se réorienter vers la Russie et le Kazakhstan où, après une décennie de crise, la demande de main-d'œuvre a fortement augmenté en raison de la croissance économique.

La projection vers l'étranger des travailleurs ouzbékistanais a en outre répondu à la législation adoptée en 2002 pour réguler les activités commerciales. Engagé dans une politique de substitution aux importations, le pays a établi des taxes à l'importation de $50 \%$ sur les produits alimentaires et de $90 \%$ sur les produits manufacturés et a limité les droits d'importation des commerçants-navetteurs, pour remédier au déséquilibre de la balance des paiements et stimuler la production nationale (Raballand, 2005). La nouvelle législation a également renforcé les contrôles sur l'origine et la qualité des produits et introduit de nouvelles démarches administratives. Ces dispositions, qui ont suscité des réactions hostiles sur les bazars, ont entravé l'activité des entreprises et des réseaux marchands, formels ou informels (Thorez, 2008). Tandis que dans les années 1990, ce secteur avait connu une forte croissance et créé de nombreux postes de travail, les mesures protectionnistes ont accentué la pression sur le marché du travail et accru le nombre de migrants potentiels. À certains égards, elles ont même été l'élément déclencheur de la massification des flux d'émigration. Les anciens commerçants-navetteurs (čelnoki) ont en effet utilisé leur expérience de la mobilité internationale pour travailler à l'étranger ou pour organiser les migrations, en recrutant et en plaçant auprès d'employeurs kazakhstanais et russes des candidats à l'émigration. Les travailleurs migrants ont aussi pu bénéficier de l'appui des entrepreneurs qui avaient délocalisé leur activité au Kazakhstan et en Russie pour se protéger des nouveaux dispositifs ouzbékistanais (Sadovskaâ, 2009). Malgré la nature différente de leur mobilité, les commerçants et les migrants mettent à profit les différentiels frontaliers et les inégalités économiques qui structurent désormais l'espace post-soviétique : en 2008, le PIB par habitant était estimé à 1030 dollars en Ouzbékistan, 8500 dollars au Kazakhstan et 11800 dollars en Russie. Ces écarts contribuent à stimuler des mobilités qui, à l'échelle de l'espace post-soviétique, aident à contenir les processus de désintégration territoriale symbolisés par les nouvelles frontières. 


\section{Migrer, un rite de transition au fondement de l'« ouzbékité »?}

Le cycle migratoire est quelquefois présenté comme un rite de transition au fondement de la construction collective de l'« ouzbékité », i.e. de l'identité de la nation ouzbèke indépendante (Massot, 2009). Expérience inédite de l'altérité, les migrations de travail renforceraient la cohésion d'une société dès lors consciente de ses « valeurs » et participeraient au changement social, à travers le statut de «nouvel Ouzbek » acquis par des migrants enrichis. Cette approche semble toutefois surestimer les effets politiques et identitaires des migrations de main-d'œuvre, alors que seuls quelques migrants travaillant en Europe de l'ouest ou en Amérique du nord ont pu réellement s'enrichir et s'élever dans la hiérarchie sociale, notamment dans les années 1990.

L'expérience migratoire apparaît en revanche essentielle dans la construction de la masculinité, en particulier dans les milieux où la proportion de femmes migrantes est faible, car migrer permet aux jeunes hommes d'affirmer leur statut social, en confirmant leur identité, en élargissant leurs compétences (Reeves, 2010). Les migrations de travail présentent ainsi des similitudes avec l'accomplissement du service militaire durant la période soviétique. Plus largement, la demande sociale stimule la mobilité des hommes, qui représentent 75 à $80 \%$ des migrants, car ces derniers migrent notamment pour se donner les moyens d'exercer leur statut de mari ou de père (Thorez, 2007a). En définitive, la société doit aujourd'hui composer avec des aspirations et des pratiques multiples, réguler les contradictions entre le départ en migration des hommes, qui déstabilise les familles, et la volonté de maintenir des structures sociales traditionnelles, en mobilisant notamment les revenus de l'émigration dans les pratiques matrimoniales.

\section{L'ESPACE MIGRATOIRE OUZBÉKISTANAIS}

\section{Flux postcoloniaux et flux globaux : les migrations internationales}

L'espace de circulation des migrants s'étend des pays du Golfe persique à l'Europe de l'ouest, de l'Amérique du nord à l'Asie orientale, région où la Corée du Sud est la principale destination des Ouzbékistanais. Mais $95 \%$ des migrants se déplacent au sein de l'ancien territoire soviétique, en direction de la Russie et du Kazakhstan (Figure 1). Révélatrice de l'hétérogénéité des projets migratoires, cette géographie de l'émigration traduit l'insertion des Ouzbékistanais dans les courants migratoires internationaux ainsi que l'ampleur des mobilités inscrites dans un contexte postcolonial : la Russie accueille entre $65 \%$ et $80 \%$ des migrants, le Kazakhstan entre $15 \%$ et $25 \%$ (Rynok..., 2007 ; Abdullaev, 2008).

\section{Un espace migratoire en expansion}

La diversification des destinations a naturellement entraîné un élargissement de l'espace migratoire, limité au territoire soviétique, sauf exception, jusqu'à la fin des années 1980. Cette extension s'opère dans un contexte de libéralisation de la mobilité quoique l'Ouzbékistan ait maintenu des dispositifs de contrôle de la circulation internatio- 


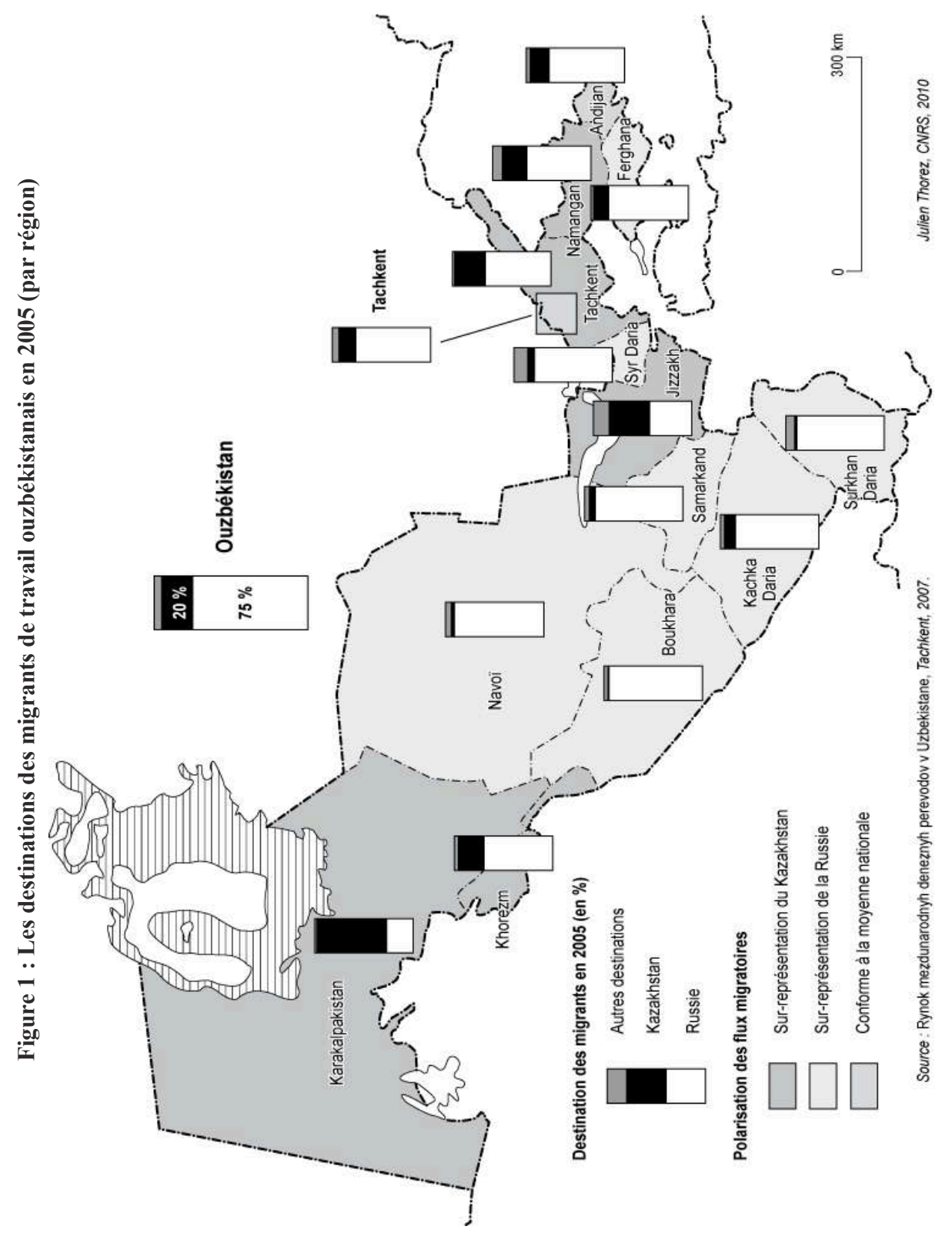


nale. La multiplication des flux d'émigration a aussi coïncidé avec l'internationalisation de la desserte de l'Ouzbékistan en particulier, le réseau des lignes aériennes internationales a connu une croissance spectaculaire depuis 1990, Tachkent étant désormais relié à plusieurs dizaines d'aéroports étrangers (Thorez, 2005). Cette évolution a toutefois moins répondu à la demande de mobilité des migrants qu'à la stratégie de développement d' $U z-$ bekistan Airways et à la demande politique de transport liée à l'affirmation de la souveraineté. À l'échelle internationale, seule la liaison Tachkent-Séoul semble connaître un essor corrélé à l'intensification des migrations de travail, plusieurs dizaines de milliers d'Ouzbékistanais travaillant en Corée du Sud.

Malgré l'internationalisation de l'offre de transport, l'« étranger lointain » reste peu accessible à la masse des travailleurs ouzbékistanais. Pourtant les destinations européennes et nord-américaines permettent aux migrants de prétendre à des revenus supérieurs aux sommes accumulées en Russie et au Kazakhstan ${ }^{12}$. Mais accéder à ces espaces implique de mobiliser des ressources économiques, culturelles et réticulaires inaccessibles à la majorité des migrants. Dans de nombreux cas, partir pour l' "étranger lointain » dépend de stratégies à long terme incluant l'apprentissage d'une langue étrangère et l'acquisition de compétences professionnelles (Belouin, 2010).

\section{Des flux polarisés par la Russie : une ancienne « métropole » accessible}

Malgré l'édification des frontières et la contraction de l'offre de transport dans les années 1990, la Russie conserve un niveau d'accessibilité élevé depuis l'Ouzbékistan, lié notamment à la proximité sociale et culturelle héritée du passé soviétique commun. Par ailleurs, conformément à l'accord signé en 1992 par les pays de la CEI qui affirme la libre circulation de leurs ressortissants, la législation russe garantit aux citoyens de l'Ouzbékistan le droit d'entrer sans visa sur le territoire national et, après enregistrement, d'y séjourner quatre-vingt-dix jours avec une autorisation temporaire de séjour, préalable à l'attribution d'une carte de séjour de trois ou cinq ans (Braux, 2009). En revanche, obtenir une autorisation de travail présente davantage de difficultés, en raison de la complexité des démarches administratives et de l'instauration d'un système de quotas ${ }^{13}$. Dès lors les migrants séjournent souvent légalement en Russie, mais y travaillent sans autorisation. Ce dispositif législatif, comme celui adopté par le Kazakhstan, amène de nombreux migrants à se rendre à l'étranger au terme d'un trimestre de présence en Russie. Ces déplacements vers le Kazakhstan ou l'Ukraine ont pour objectif de franchir la frontière et de retourner légalement en Russie. Il arrive aussi qu'une personne - elle-même migrante - se charge des passeports de plusieurs collègues et négocie à la frontière la régularisation des documents.

12 En moyenne, en 2007, les migrants dégageaient 100 dollars par mois en Russie, 300 dollars en Corée du Sud et 800 dollars aux États-Unis (Rynok..., 2007).

13 En 2007, après l'instauration d'un système de quotas, la Russie a établi une liste de secteurs d'activité, de métiers et de qualifications prioritaires : travaux de construction, de rénovation et de montage ; travailleurs agricoles qualifiés ; industries métallurgique et automobile ; chauffeurs et machinistes (Braux, 2009).

REMI 2010 (26) 3 pp. 31-57 


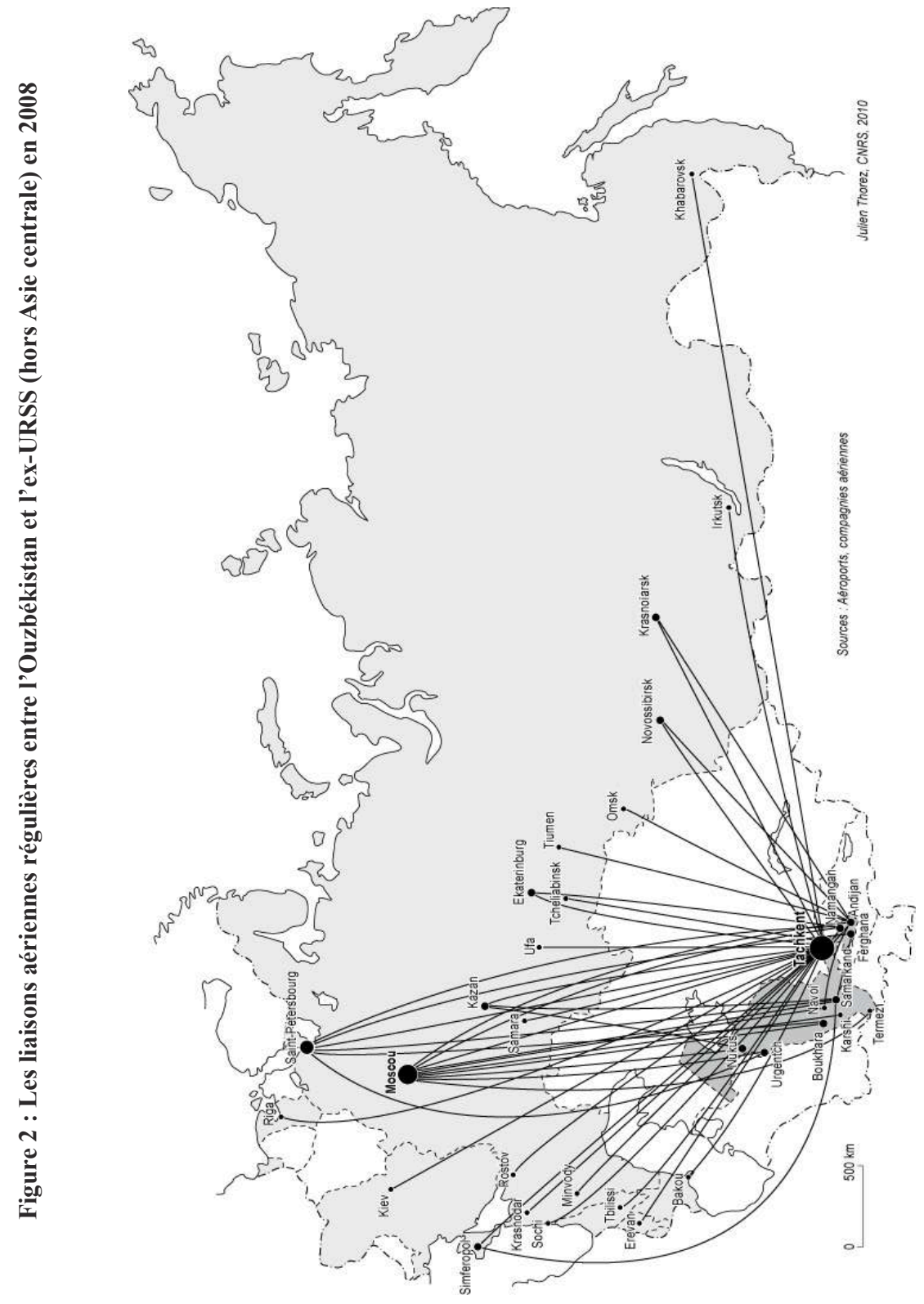


Un dense réseau de liaisons aériennes, ferroviaires et routières fait toujours de la Russie et de Moscou le pays et la ville les mieux desservis depuis l'Ouzbékistan (Figure 2). En 2009, trente-six lignes aériennes connectent onze villes ouzbékistanaises à dix-sept villes russes; les chemins de fer ouzbékistanais et russes exploitent huit liaisons au départ de Tachkent ; des centaines d'autocars et de minibus circulent entre les deux pays. Depuis le début des années 2000, l'offre de transport connaît une forte croissance soutenue à l'évidence par la mobilité des migrants, sans toutefois retrouver son niveau soviétique (Figures 2, 3 et 4). Elle se traduit par l'ouverture de nouvelles lignes aériennes et ferroviaires, notamment à destination de Saint-Pétersbourg, et par une augmentation de la fréquence de circulation des avions et des trains (Figures 2 et 3 ). En dépit du renforcement de l'offre de transport, des pénuries de billets peuvent survenir au printemps et en automne, périodes où la demande de mobilité est maximale, par exemple sur la liaison Tachkent-Moscou.

Les coûts de transport n'entravent pas la mobilité des travailleurs ouzbékistanais, malgré leur augmentation depuis 1990. La plupart des familles peuvent rassembler le capital suffisant pour financer le voyage d'un migrant d'autant que travailler en Russie permet généralement de rembourser rapidement les dettes contractées auprès de parents et/ou d'amis. En 2008, 200 euros suffisaient pour acheter un billet d'avion pour Ufa, Rostov, Tcheliabinsk ou Novossibirsk. Un billet de train en seconde classe coûtait entre Tachkent et Saratov 140000 sum (soit soixante-dix euros), entre Tachkent et Moscou 260000 sum (soit 130 euros) $)^{14}$. Le transport routier offre des tarifs moins coûteux, mais depuis l'Ouzbékistan, quatre à cinq jours sont nécessaires pour atteindre les régions centrales de la Russie. Ces possibilités de circuler aisément et légalement permettent à de nombreux travailleurs de se rendre en Russie au printemps et de rentrer en Ouzbékistan à l'automne. Ces mobilités saisonnières rythment désormais la vie des villes et des villages d'Ouzbékistan et l'on observe notamment le glissement vers l'hiver des cérémonies de mariage et de circoncision.

La localisation des villes desservies depuis l'Ouzbékistan témoigne de la dispersion des migrants sur l'ensemble du territoire russe (Figure 2). Toutefois, les régions centrales (Moscou et Saint-Pétersbourg) et les régions voisines de l'Asie centrale (ensemble VolgaOural, Sibérie occidentale) accueillent la majorité des migrants (Zajončkovskaâ, 2008) Plusieurs centaines de milliers d'Ouzbékistanais résident ainsi dans l'agglomération moscovite où, à l'instar des migrants tadjikistanais et kirghizstanais, ils travaillent dans les secteurs de la construction, de l'entretien, de la restauration, des services et du commerce, malgré l'entrée en vigueur en 2006 d'une loi interdisant aux étrangers d'exercer la profession de vendeur sur les marchés (Maksakova, 2009 ; Braux, 2009). Dans les régions méridionales, les migrants sont également embauchés dans l'agriculture, en particulier dans la production de fruits et légumes. La présence massive de la main-d'œuvre centre-asiatique en Russie, accompagne le développement économique, compense partiellement le

14 En 2000, selon les catégories de confort, le billet de train Tachkent-Moscou coûtait de 23840 à 35000 sum (de trente à quarante-cinq dollars) (Thorez, 2005).

15 En 2007, un quart des migrants ouzbékistanais travaillait à Moscou, près de $20 \%$ dans l'okrug fédéral de la Volga, près de $15 \%$ dans l'okrug fédéral de Sibérie, d'après le service fédéral des migrations.

REMI 2010 (26) 3 pp. 31-57 


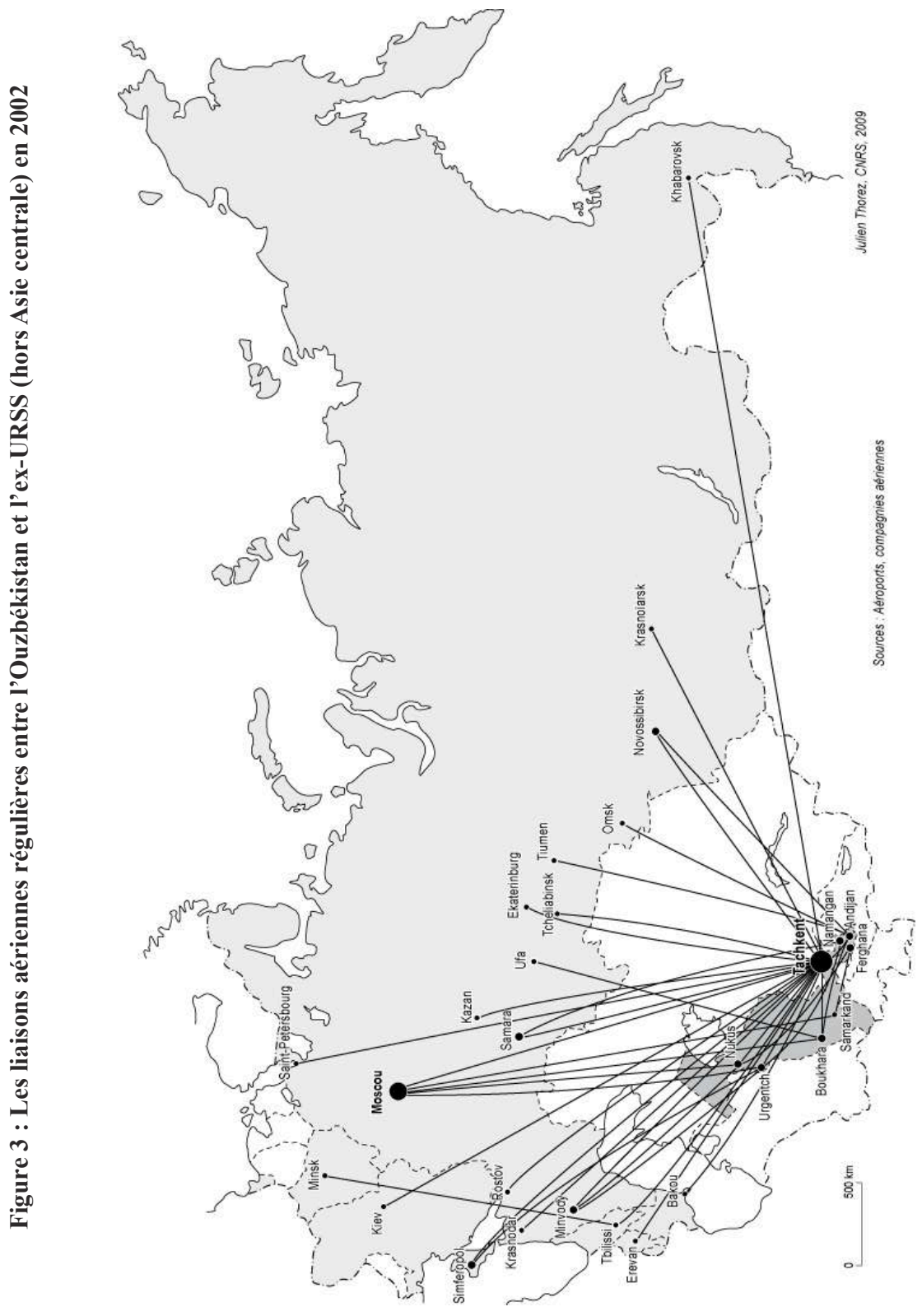


déficit démographique, mais ne va pas sans poser des questions sociales et politiques à une société affectée par des tendances xénophobes ${ }^{16}$. Dans ce contexte, la politique migratoire russe oscille entre des mesures de fermeté et des décisions inspirées par des positions plus libérales (Zajončkovskaâ, Mkrčân et Tûrûkanova, 2009).

\section{Flux locaux et flux régionaux : des migrations centre-asiatiques dirigées vers le Kazakhstan}

En Asie centrale, la mobilité des travailleurs ouzbékistanais se fait sous la forme de flux locaux dirigés vers les régions limitrophes du Kirghizstan et du Kazakhstan et de flux régionaux orientés vers les principaux pôles économiques du Kazakhstan : les régions pétrolières d'Aktau et d'Atyrau, la capitale économique, Almaty, et la capitale politique, Astana.

À l'échelle locale, les flux migratoires se sont développés dans les viloyat de Tachkent, de Syr Daria et de Djizakh en direction du Kazakhstan du Sud. Ces migrations intéressent surtout des ouvriers agricoles engagés pour la saison, le mois, la semaine ou la journée, à la production de fruits et de légumes ou à la cueillette du coton dans les districts de Sary Agach et de Makhtaaral. En 2001, bien que moins payés que la maind'œuvre locale, les ramasseurs de coton travaillant au Kazakhstan, qui viennent aussi des régions pauvres du Kachka Daria et du Surkhan Daria, pouvaient presque tripler leurs revenus (Thorez, 2005 ; Sadovskaâ, 2009). Embauchés également dans les secteurs de la construction et du commerce, les nombreux migrants participent activement au développement économique du Kazakhstan du Sud (Trudovye..., 2005 ; Sadovskaâ, 2009) ${ }^{17}$. Plus à l'ouest, le bassin caspien attire un quart des travailleurs ouzbékistanais, principalement originaires du Karakalpakistan et du Khorezm (Figure 1). Une minorité de migrants, souvent issus du Ferghana et de la région de Samarkand, se dirigent vers Almaty et Astana, où la construction, la restauration et le commerce sont leurs principaux domaines d'activité (Sadovskaâ, 2009).

La présence des travailleurs ouzbékistanais était également importante dans le Ferghana kirghizstanais, dans les régions d'Och et de Djalal-Abad, où leur séjour était de courte durée ${ }^{18}$. Originaires des régions de Namangan, de Ferghana et surtout d'Andijan, les migrants travaillaient dans l'agriculture ainsi que dans la construction, de nombreux travaux étant effectués par des brigades présentes au Kirghizstan le temps d'un chantier. Ce flux, qui chaque jour drainait 4000 à 5000 travailleurs (Èlebaeva, 2004), s'est toutefois brutalement tari à la suite des violences interethniques survenues en juin 2010 dont les principales victimes furent les populations ouzbèkes du Kirghizstan.

16 Pour un travail équivalent, le salaire des migrants d'Asie centrale correspond à 30 à $40 \%$ du salaire des Moscovites (Zajončkovskaâ, Mkrčân et Tûrûkanova, 2009).

17 Laruelle avance qu'entre 0,2 et 1 million de migrants ouzbékistanais travailleraient dans l'oblast' du Kazakhstan du Sud, entre 1 et 2 millions au Kazakhstan (Laruelle, 2010b), mais d'autres chercheurs estiment que le nombre de migrants présents au Kazakhstan oscillerait entre 0,7 et 1,2 million (Sadovskaâ, 2009).

18 La présence des migrants a suscité à plusieurs reprises des réactions d'hostilité dans les districts agricoles de la région de Djalal-Abad.

REMI 2010 (26) 3 pp. 31-57 
En Asie centrale, la circulation des personnes ne présentait aucune difficulté jusqu'à la décision des États de fonctionnaliser les nouvelles frontières internationales, à la fin des années 1990. Aujourd'hui des contraintes inédites affectent en revanche les mobilités transfrontalières : la frontière kazakhstano-ouzbékistanaise a plusieurs fois été partiellement fermée, de même que la frontière kirghizstano-ouzbékistanaise. Cependant, les autorités kazakhstanaises n'exigent pas des ressortissants ouzbékistanais la possession d'un visa bien que les migrants doivent se soumettre aux contrôles " pointilleux » des gardes-frontières, des douaniers et des policiers. Quoique des itinéraires clandestins existent dans l'oasis de Tachkent, la quasi-totalité des migrants entre donc légalement au Kazakhstan, mais nombre d'entre eux se voient contraints de verser un pot-de-vin (Alimbekova et Šabdenova, 2009). Au Kazakhstan, les démarches pour obtenir un permis de résidence ou une autorisation de travail de même que l'absence de document lors d'un contrôle de police nourrissent également une corruption à grande échelle (Trudovye..., 2005) ${ }^{19}$.

En raison de la proximité du Kazakhstan et du Kirghizstan, le transport routier est le principal moyen utilisé par les migrants. Toutefois, depuis la fermeture des frontières, aucune ligne régulière d'autocar n'assure plus de liaison transfrontalière. Pour s'affranchir de cette contrainte, une gare routière informelle a été implantée au nord du poste-frontière de Tchernaevka situé sur la route Tachkent-Chymkent. Reliée aux villes kazakhstanaises et russes, elle fait office pour Tachkent de gare routière internationale. Plus au sud, l'accès à la région du Jetisaï, appendice méridional du Kazakhstan, constitue un cas particulier, car la route Tachkent-Samarkand transitait par cette région cotonnière rattachée à la Steppe de la Faim. À l'automne, soir et matin, des centaines de ramasseurs de coton attendaient sur les bas-côtés de la route de monter dans une voiture, un minibus, un autocar ou un camion pour faire les quelques kilomètres séparant leur village des champs kazakhstanais. Pour limiter les mobilités transfrontalières, les autorités ouzbékistanaises ont décidé de fermer cette route en 2003 (Thorez, 2005). Mais certains taxis continuent de relier les bourgs ouzbékistanais aux villages kazakhstanais et s'improvisent intermédiaires entre les migrants et les employeurs, non sans prélever des sommes importantes aux migrants, avant de leur restituer leur passeport une fois la frontière franchie (Kamalova, 2005).

À l'échelle de l'Asie centrale, les migrations de travail connaissent une ampleur et une géographie inédites, malgré les entraves à la mobilité et la crise économique survenue en 2008. Alors que le Kazakhstan, premier pôle économique centre-asiatique, est devenu une destination majeure des migrants ouzbékistanais, ces flux de main-d'œuvre redéfinissent les relations entre l'Ouzbékistan et le Kazakhstan et remodèlent les équilibres géopolitiques régionaux.

\section{Tachkent, une capitale-relais ? Les migrations nationales}

À l'instar des migrations internationales, les migrations nationales sont devenues un phénomène social et économique majeur. Ces flux caractérisés par une surreprésentation des ruraux par rapport à leur poids dans la population et des femmes par rapport à leur

19 En 2005, un rapport estimait que les services de sécurité kazakhstanais avaient reçu plus de 15 millions de dollars des migrants, les sommes s'échelonnant en moyenne de 200 tenge $(1,5 \$)$ pour une absence de carte d'immigration à 1200 tenge (9 \$) pour l'obtention d'un enregistrement et à 32500 tenge $(240 \$)$ pour l'obtention d'un permis de résidence d'un an (Trudovye..., 2005). 
place dans les flux internationaux, sont polarisés par Tachkent (Maksakova, 2008) ${ }^{20}$. Si les villes de province, au premier rang desquelles Samarkand, reçoivent des migrants originaires des campagnes environnantes, Tachkent accueille les trois quarts des migrants intérieurs et recrute des travailleurs sur l'ensemble du territoire national (Maksakova, 2005 ; Abdullaev, 2008). Dans ce cadre, les régions méridionales (Surkhan-Daria, Kachka-Daria) et orientales (Ferghana) fournissent une part importante des migrants.

Les contrôles administratifs sur la mobilité résidentielle et professionnelle hérités de la période soviétique - les embauches sont toujours officiellement consignées dans le livret de travail des salariés - ne sont pas un obstacle à la circulation des travailleurs en Ouzbékistan $^{21}$. Pour leurs déplacements, ces derniers bénéficient d'une offre de transport diverse, malgré la contraction des réseaux aériens et ferroviaires domestiques depuis 1991 (Thorez, 2005) ${ }^{22}$. Alors que la compagnie ferroviaire O'zbekiston temir yo'llarl a mis en service des trains rapides sur l'axe Tachkent-Boukhara, le transport routier a vu son rôle croître dans la desserte du territoire national, notamment pour les liaisons interrégionales (Thorez, 2007b). Des autocars relient les régions occidentales et méridionales à Tachkent, mais les migrants empruntent également des taxis et des taxis collectifs interurbains, en particulier entre le Ferghana et Tachkent, car le franchissement du Tian-Chan est interdit aux autocars. Le soutien de l'État au secteur des transports, inspiré de la politique soviétique, permet en outre de pratiquer des tarifs contenus sur les trajets domestiques : en 2008, un billet de train entre Samarkand et Tachkent coûtait 9250 sum (cinq euros).

Parmi les travailleurs ruraux et provinciaux qui se rendent à Tachkent, certains connaissent préalablement leur destination professionnelle. C'est le cas de la plupart des hommes qui se déplacent à l'occasion d'un chantier de construction, au sein d'une équipe de travail dirigée par un brigadir. En général, ce dernier, qui est un membre de la famille, un ami ou une connaissance, se met d'accord en amont avec un intermédiaire ou un employeur. Dans ce cadre, migrent aussi bien des travailleurs inscrits dans la migration, qui sont souvent qualifiés, que des jeunes hommes désireux de gagner ponctuellement de l'argent en s'embauchant pour quelques semaines ${ }^{23}$. À Tachkent, cette mobilité entraîne une division géographique du travail sur les chantiers de construction : les brigades provinciales se chargent du gros œuvre, tandis que des équipes tachkentoises effectuent les finitions (Bazin, 2009). Toutefois, nombreux sont les migrants qui se déplacent à la recherche d'un travail non défini et qui rejoignent les rangs des mardikor, attendant dès l'aube, sur les bazars ou le long des routes, d'être embauchés pour la journée ou pour une durée un peu plus longue, comme soudeurs, bétonneurs, manœuvres, couvreurs ou agents d'entretien (Allahverdieva, 2007). Si des formes de travail journalier existaient

20 Parmi les déplacements saisonniers, la mobilité des travailleurs réquisitionnés pour la cueillette du coton apparaît rarement dans les travaux consacrés aux migrations de travail, en dépit de l'importance du phénomène.

21 Les migrations vers Tachkent sont également le fait d'étudiants attirés par la diversité de l'offre de formation proposée par les institutions d'enseignement supérieur.

22 Actuellement, un train par semaine relie Tachkent à Andijan, tandis que la liaison était assurée trois fois par jour à la veille de la partition de l'URSS.

23 En 2008, des jeunes étudiants venus du Khorezm pouvaient ainsi accumuler 150 à 200 dollars pendant l'été. 
durant la période soviétique, le mardikor est devenu au cours des dernières années une figure typique du monde du travail et un des visages des migrants. À Tachkent, des usines textiles emploient aussi des migrants d'origine rurale, moins payés et plus dociles que la main-d'œuvre locale, et organisent leur mobilité quotidienne (Bazin, 2009). Ces migrations pendulaires dessinent les contours d'un vaste bassin d'emploi autour de la capitale.

La place centrale occupée par Tachkent dans le système migratoire ouzbékistanais tient aussi à la fonction d'interface assurée par la ville entre les espaces migratoires nationaux et internationaux. Migrer vers Tachkent est souvent une première étape vers l'étranger. Les migrants y acquièrent des compétences professionnelles et linguistiques, à travers l'apprentissage du russe et nombreux sont ceux qui envisagent et organisent leur séjour dans la capitale comme un moment dans leur parcours migratoire individuel ou familial. Des familles ouzbékophones, reportant sur leurs enfants le projet de quitter l'Ouzbékistan les inscrivent ainsi dans des écoles où l'enseignement s'effectue en russe. Dans les grands quartiers résidentiels, tel Tchilanzar, des écoles ouzbèkes voient donc leurs effectifs diminuer tandis que la demande augmente fortement dans les écoles russes. Cela dit, la perspective de migrer oriente les choix scolaires partout en Ouzbékistan : dans toutes les régions, les effectifs des collèges préparant aux métiers du bâtiment (et de la restauration) croissent depuis plusieurs années (Abdullaev, 2008).

\section{Des qishloq à New York : un système migratoire hiérarchisé}

La mobilité des travailleurs ouzbékistanais prend des formes nationales ou internationales, mais les réseaux qui lient les lieux d'émigration et les lieux d'immigration structurent un système migratoire cohérent. Partir pour les États-Unis, la Corée du Sud, la Russie ou pour le Kazakhstan nécessite de mobiliser des ressources différentes que pour migrer vers Tachkent, mais les expériences migratoires présentent souvent des points communs. Les travailleurs migrants sont partout confrontés à des législations contraignantes qui reposent sur la délivrance de permis de résidence et de travail. De ce fait, la majorité des migrants habite et travaille illégalement à Tachkent tant il est difficile d'obtenir un enregistrement auprès des autorités compétentes. Dès lors de nombreux migrants, en particulier les mardikor, sont dépendants de la police, à l'instar de leurs homologues de Russie ou du Kazakhstan, et sont, selon Bazin, placés en situation « d'asservissement collectif » (2009). Pourtant, en Ouzbékistan, les relations avec la police ne semblent pas perçues comme un problème par les migrants (Abdullaev, 2008). Un autre parallèle peut être fait concernant les conditions d'hébergement tant la description des logements des travailleurs ouzbékistanais en Corée du Sud, en Russie ou au Kazakhstan fait écho à la vie quotidienne des migrants à Tachkent (Brusina, 2008 ; Massot, 2009). Une grande partie d'entre eux réside dans des appartements loués collectivement, au mépris des règles d'hygiène et des normes sociales, ou sur leur lieu de travail (Abdullaev, 2008) ${ }^{24}$. À Moscou, à Astana comme à Tachkent, les ouvriers du bâtiment, notamment ceux qui font le gros œuvre, habitent souvent sur les chantiers dans des baraquements et sont alors « captifs de leur lieu de travail » (Bazin, 2009).

24 De nombreux mardikor louent une place pour la nuit dans un appartement ou une maison qu'ils partagent avec d'autres migrants, souvent hommes et femmes mélangés. En 2007, ils dépensaient en moyenne 500 sum par jour pour se loger (Allahverdieva, 2007). 
Tableau 2 : La hiérarchie des migrations de travail ouzbékistanaises

\begin{tabular}{|c|c|c|c|}
\hline Hiérarchie & \multicolumn{2}{|c|}{ Nature des migrations } & Destinations \\
\hline \multirow{7}{*}{-} & \multirow{2}{*}{\multicolumn{2}{|c|}{ Nationales }} & Villes de province \\
\hline & & & Tachkent \\
\hline & \multirow{7}{*}{ Internationales } & \multirow[b]{2}{*}{ Régionales } & Kazakhstan du Sud \\
\hline & & & $\begin{array}{l}\text { Kazakhstan : Almaty, Astana, régions } \\
\text { caspiennes }\end{array}$ \\
\hline & & Postcoloniales & Russie \\
\hline & & \multirow{4}{*}{ Globales } & Émirats arabes unis \\
\hline & & & Corée du Sud \\
\hline \multirow{2}{*}{+} & & & Europe \\
\hline & & & Amérique du Nord \\
\hline
\end{tabular}

Les trajectoires migratoires s'inscrivent dans une hiérarchie des destinations qui dépend du niveau d'accessibilité, des opportunités économiques et du prestige des lieux d'immigration (Tableau 2). Les itinéraires des migrants témoignent de la fluidité qui existe entre les sous-ensembles de l'espace migratoire, en particulier au sein de l'espace postsoviétique, et qui donne sa cohérence au champ migratoire. Si la majorité des migrants privilégie des stratégies fondées sur la stabilité de leur implantation à l'étranger, la perspective d'améliorer la réussite économique et sociale de la migration conduit certains d'entre eux à se diriger vers de nouvelles destinations plus profitables bien que moins accessibles. Inversement, après avoir travaillé plusieurs saisons en Russie, des migrants peuvent choisir de se rendre au Kazakhstan, car sa proximité géographique permet de revenir plus fréquemment au qishloq, par exemple après une naissance ou durant une période de deuil. À cet égard, il convient d'appréhender avec souplesse la hiérarchie des destinations d'autant que les choix migratoires s'inscrivent dans des contextes locaux qui participent à l'orientation géographique de la mobilité des travailleurs. Dans les villes comme dans les villages, les réseaux de sociabilité mobilisés au cours de la migration contribuent à déterminer la destination des migrants : les habitants d'un quartier, d'un village voire d'un district tendent à se diriger vers les mêmes lieux (Reeves, 2010).

\section{LES MIGRATIONS DE TRAVAIL, UNE GÉOPOLITIQUE « PAR LE BAS »}

\section{Ambiguïtés ouzbékistanaises : entraver ou accompagner les migrations?}

Malgré l'ampleur des flux, les autorités refusent de faire de la question migratoire un élément important de leurs politiques étrangère et économique, à la différence du Tadjikistan et du Kirghizstan. Alors que l'Ouzbékistan n'a pas signé les conventions 
internationales élaborées sous l'égide de l'ONU sur les migrations de travail, l'État semble apporter un soutien limité à ses ressortissants émigrés. Ainsi, il n'existe pas d'accord bilatéral entre l'Ouzbékistan et le Kazakhstan sur le statut des migrants de travail (Laruelle, 2010b). En Russie, aucun réseau associatif comparable à ceux des communautés tadjikistanaises ou kirghizstanaises n'assure l'interface entre les migrants et les autorités ouzbékistanaises et russes. Cette attitude renvoie au refus de l'État de reconnaître combien l'externalisation de la main-d'œuvre modèle la société et l'économie (Laruelle, 2010a). À bien des égards, elle traduit également la volonté du pouvoir de conduire une politique de limitation des migrations, conçue au nom d'enjeux sécuritaires comme un outil de contrôle de la population et du territoire.

Depuis l'essor des migrations de travail, la législation a ainsi été amendée à plusieurs reprises au détriment de la liberté de circuler et de travailler à l'étranger (Ilkhamov, 2006). En 2003, l'État a décidé de soumettre à l'autorisation d'une commission interministérielle le droit de travailler à l'étranger, avant d'introduire de nouveaux dispositifs contraignants en 2005 et en 2007. Outre le contrôle de la mobilité, ces mesures ont permis à l'administration de s'impliquer davantage dans la régulation d'un secteur très lucratif, la complexité des démarches ouvrant un vaste espace de négociation informel entre migrants et représentants des services de l'État. Plus largement, l’État semble tenter de contenir un processus qui questionne sa souveraineté et sa légitimité (Massot, 2009).

La politique migratoire ne se limite cependant pas à cet aspect. Les autorités disposent d'une part d'une connaissance fine du phénomène migratoire, grâce aux informations recueillies à l'échelle des mahalla et au travail d'analyse effectué par les administrations centrales. D'autre part, malgré la discrétion des représentants des ministères et des administrations, de nombreux documents officiels, émanant par exemple du Praesidium du Cabinet des ministres, abordent clairement la question des migrations de travail et de leurs conséquences sur la situation économique et sociale. Enfin, la prudence affichée par l'État vis-à-vis des migrations n'a pas empêché le pays de signer plusieurs accords bilatéraux. En 1995, un accord a été conclu avec la Corée du Sud, impliquant notamment la Fédération coréenne des petites et moyennes entreprises. En 2007, 1'Ouzbékistan et la Russie ont signé plusieurs accords, ratifiés en 2009, qui portent sur la défense des droits des travailleurs-migrants, sur la lutte contre les migrations clandestines et sur le rapatriement des migrants illégaux expulsés. Ces accords sont censés déboucher sur un progrès significatif du statut des travailleurs ouzbékistanais en Russie. La participation de l'Ouzbékistan à la structure interétatique qui regroupe depuis 2008 les administrations des migrations des pays de la CEI doit également permettre d'améliorer les conditions de circulation, de résidence et de travail des migrants (Maksakova, 2009).

L'implication des autorités ouzbékistanaises dans la régulation des flux migratoires repose aussi sur le rôle joué par les entreprises de transport détenues par l'État dans la circulation internationale des migrants. Or, depuis le début des années 2000, Uzbekistan Airways et Uzbekistan Railways ont orienté leur développement sur les liaisons entre l'Ouzbékistan et la Russie (Figures 2 et 3). En 2000, Uzbekistan Airways assurait vingtsept vols hebdomadaires à destination de treize villes russes ; en 2008, elle opérait soixantetrois vols hebdomadaires en direction de seize aéroports de Russie. Après avoir été un outil d'affirmation de la souveraineté nationale dans les années 1990, Uzbekistan Airways 
contribue aujourd'hui à l'intensification des circulations migratoires. Ce repositionnement stratégique possède une dimension économique évidente en répondant à l'augmentation de la demande de transport à destination de la Russie. Mais il participe aussi d'une volonté politique qui vise non seulement à tolérer la mobilité des migrants, mais également à accompagner voire à encourager le développement des migrations de main-d'œuvre.

\section{Les dépendances postcoloniales d'un pays du Sud ?}

La nouvelle territorialité des populations centre-asiatiques est un des vecteurs d'intégration de l'Ouzbékistan dans l'espace mondialisé. Les flux migratoires contribuent à l'ouverture internationale de la société et de l'économie de même qu'à la réévaluation du positionnement géopolitique et géoéconomique du pays et notamment à la reformulation des relations entretenues avec la Russie. Le rapprochement diplomatique entre l'Ouzbékistan et la Russie opéré en 2005 a souvent été relié à la condamnation occidentale de la répression de l'insurrection d'Andijan. Mais ce virage politique renvoie également à la réactivation des dynamiques d'intégration régionale suscitée par les migrations de maind'œuvre.

Cette « géopolitique par le bas » repose sur l'intensification des migrations de travail et sur le développement des réseaux de transports. Inscrite dans un schéma postcolonial classique, elle marque une évolution profonde des relations entre l'Ouzbékistan et la Russie, en raison de la dépendance économique et sociale qui naît des flux migratoires. La mobilité des travailleurs s'accompagne en effet d'importants transferts de capitaux qui irriguent l'économie domestique. Chaque année, plusieurs milliards de dollars (officiellement, 3 milliards de dollars en 2008) pénètrent sur le territoire ouzbékistanais par l'entremise des migrants (Maksakova, 2009). Cette opération est assurée par des entreprises de transfert d'argent, mais les experts estiment qu'une somme au minimum équivalente au capital officiellement transféré est illégalement transmise par les migrants (Rynok..., 2007). Différents réseaux informels, notamment commerçants, permettent d'expédier de l'argent ; des biens (hifi, électroménager, prêt-à-porter) peuvent aussi être envoyés, en particulier depuis la Corée du Sud, pour être revendus en Ouzbékistan par la famille. Ces flux de capitaux, qui représentent selon les estimations entre $10 \%$ et $25 \%$ du PIB, instituent à l'échelle des familles une dépendance à l'endroit de la Russie (et du Kazakhstan), laquelle se substitue aux formes d'interdépendance construites entre les différentes régions soviétiques à l'échelle des administrations et des entreprises.

L'évolution de la géographie des liaisons aériennes entre l'Ouzbékistan et la Russie depuis la disparition de l'URSS rend également compte du changement de statut de l'Ouzbékistan. Malgré une croissance régulière durant les années 2000, l'offre de transport apparaît moins développée aujourd'hui qu'à la fin de la période soviétique, quand Tachkent était le second aéroport d'URSS pour les liaisons moyen et long-courrier (Figures 2, 3 et 4). Mais davantage de villes d'Ouzbékistan sont aujourd'hui reliées à la Russie qu'en 1985, quand les liaisons directes étaient pourtant privilégiées au détriment des hubs dans le système de transport soviétique (Sagers et Maraffa, 1990 ; 1991). Cette transformation du réseau, qui correspond à l'établissement de lignes régulières entre tous les centres régionaux et Moscou, est parallèle à la rétraction de l'espace desservi en Russie depuis l'Ouzbékistan (Figures 2, 3 et 4). Cette dynamique affecte la desserte des 


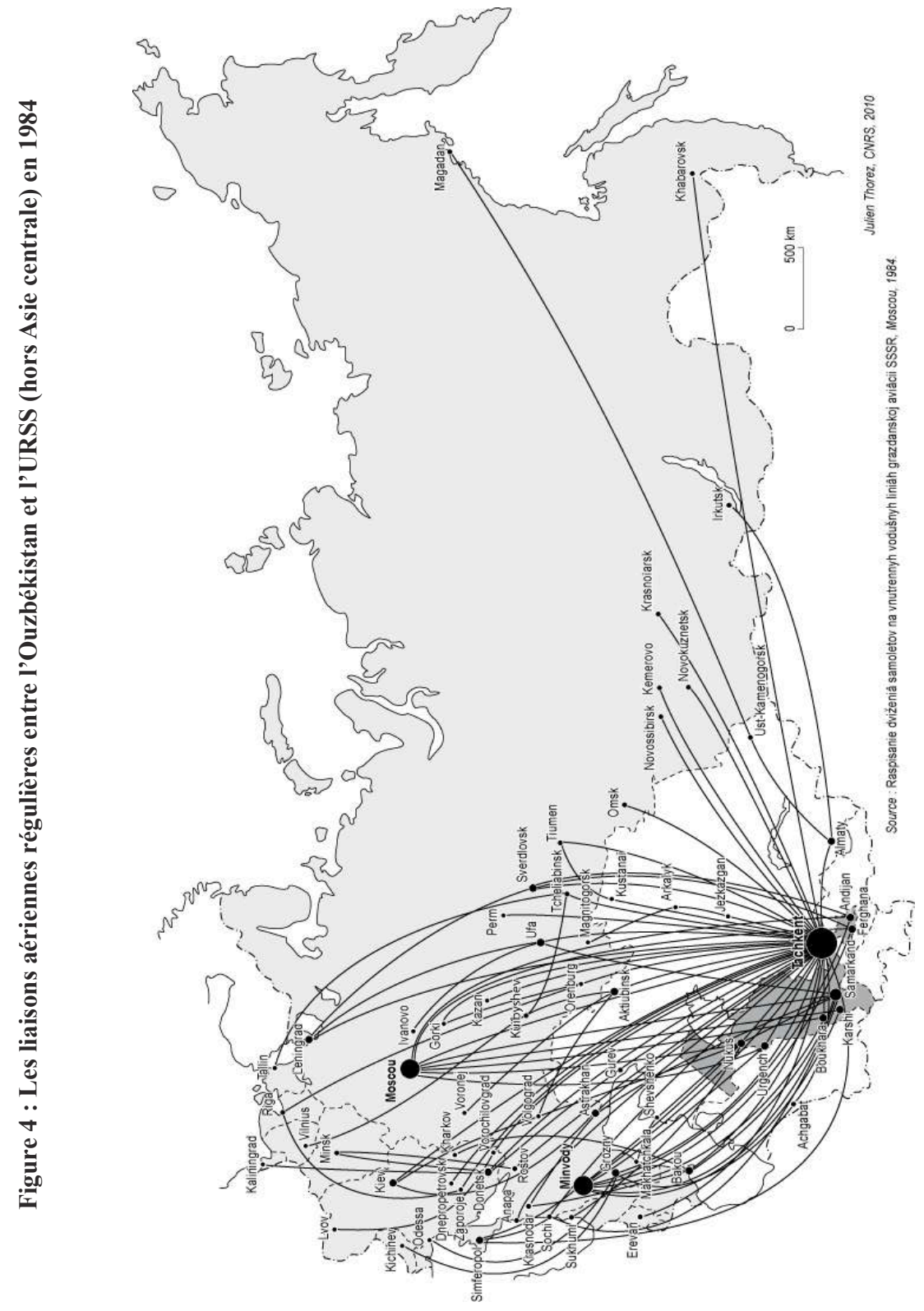


villes moyennes, mais surtout celle des régions touristiques. Au milieu des années 1980, Minvody, située sur le piémont septentrional du Caucase, au cœur d'une grande région thermale, était reliée à huit aéroports ouzbékistanais et était ainsi après Moscou l'aéroport le mieux connecté à l'Ouzbékistan ; aujourd'hui, un vol hebdomadaire est opéré depuis Tachkent par Uzbekistan Airways (Figures 2 et 4). Cette mutation du réseau aérien répond à la reformulation de la demande de transport qui conduit les mobilités laborieuses à se substituer aux mobilités touristiques. Cette évolution structurelle révèle la transformation profonde de l'architecture géoéconomique et géopolitique du monde post-soviétique et traduit le glissement de l'Ouzbékistan vers le Sud.

\section{CONCLUSION}

Les migrations de travail saisonnières et temporaires, qui furent souvent interprétées comme une réponse à la crise post-soviétique, sont désormais ancrées durablement dans les pratiques individuelles et collectives ${ }^{25}$. La société ouzbékistanaise, profondément transformée, s'inscrit à moyen et long terme dans cette forme de mobilité inédite : une enquête réalisée pour l'administration a montré que $85 \%$ des familles interrogées ne concevaient pas leur avenir sans la migration de l'un de ses membres (Rynok..., 2007) ; une première génération de migrants transmet son expérience de l'étranger et ses réseaux professionnels à des successeurs dont la formation en Ouzbékistan est de plus en plus déterminée par la demande extérieure. Si la crise économique survenue en 2008-2009 a réduit l'activité en Russie et au Kazakhstan, de sorte que des migrants ont annulé ou anticipé leur retour au pays ou bien retardé leur départ, les flux migratoires s'intensifient de nouveau, de même qu'au Tadjikistan ou au Kirghizstan. En une décennie, l'Ouzbékistan est devenu un pays de migrants et de familles de migrants, dont le développement repose de plus en plus sur l'externalisation de la main-d'œuvre, en contradiction avec la politique économique protectionniste suivie depuis l'indépendance.

Les migrations de main-d'œuvre contribuent, parallèlement à l'action diplomatique conduite par les autorités, à redéfinir le positionnement international de l'Ouzbékistan, en interrogeant son modèle de développement et sa place dans le monde contemporain. Polarisées par la Russie, elles tendent à ancrer l'Ouzbékistan dans une situation post-coloniale classique. Mais leur apparition puis leur généralisation illustrent aussi la spécificité de la trajectoire suivie depuis l'indépendance par l'Ouzbékistan (et par les pays du Caucase et de l'Asie centrale); son itinéraire post-soviétique s'apparentant à une forme de décrochage du Nord vers le Sud.

25 Des migrants « centre-asiatiques » d'Ouzbékistan envisagent une installation définitive à l'étranger, mais ils restent minoritaires. 


\section{Références bibliographiques}

ABDULLAEV E.V. (Éd.) (2008) Trudovaâ migraciâ v respublike Uzbekistan [Les migrations de travail en Ouzbékistan], Tashkent, UNDP, 204 p.

ALIAKBEROVA N.M., GOL'DFARB B.Â. et ÈRGAŠEV A. (1989) Razmeŝenie naseleniâ ferganskoj doliny (demografičeskij aspekt) [La répartition de la population de la vallée du Ferghana (aspects démographiques)], Tachkent, Fan, 98 p.

ALIMBEKOVA G.T. et ŠABDENOVA A.A. (2009) Zanâtost' trudâsihihsâ-migrantov v neformal'noj èkonomike Kazahstana [L'emploi des migrants de travail dans l'économie informelle au Kazakhstan], Almaty, IOM, 40 p.

ALLAHVERDIEVA L.M.(2007) Neformal'nye rynki truda i problemy vnutrennoj migracii naseleniâ Uzbekistana [Les marchés informels du travail et les migrations intérieures en Ouzbékistan], in Naselenie Uzbekistana: 15 let nezavisimogo razvitiâ, Tachkent, Centr social'no-èkonomičeskih issledovanij, UNFPA, pp. 71-76.

ARTYKOVA D.A. (2007) Feminizaciâ trudovoj migracii [La féminisation des migrations de travail], in Naselenie Uzbekistana: 15 let nezavisimogo razvitiâ, Tashkent, Centr social'noèkonomičeskih issledovanij, UNFPA, pp. 142-144.

BATER James H. (1989) The Soviet Scene. A Geographical Perspective, London, Edward Arnold, $304 \mathrm{p}$.

BAZIN Laurent (2009) Paysans ouvriers, in Laurent Bazin, Monique Selim et Bernard Hours Éds, L'Ouzbékistan à l'ère de l'identité nationale, Paris, L'Harmattan, 368 p.

BELOUIN Stéphanie (2010) Projets et stratégies migratoires de femmes qualifiées à Tachkent, in Marlène Laruelle Éd., Dynamiques migratoires et changements sociétaux en Asie centrale, Paris, Pétra, pp. 297-318.

BRAUX Adeline (2009) Politique migratoire et gestion de la diversité culturelle en Russie : l'exemple de Moscou, Paris, Les études du CERI, 158, $37 \mathrm{p}$.

BRUSINA O. (2008) Migranty iz Srednej Azii v Rossii: ètapy i pričiny priezda, social'nye tipy, organizacii diaspor [Les migrants d'Asie moyenne en Russie : étapes et causes migratoires, profil social et organisation des diasporas], Vestnik Evrazii, 2 (40), pp. 66-95.

ÈLEBAEVA A.B. (2004) Trudovye migracii v Kyrgyzstane [Les migrations de travail au Kirghizstan], Central'naâ Aziâ i Kavkaz, 27, pp. 78-86.

FERRANDO Olivier (2010) Politiques diasporiques et flux migratoires : les États-nations et leurs minorités co-ethniques de l'étranger, in Marlène Laruelle Éd., Dynamiques migratoires et changements sociétaux en Asie centrale, Paris, Pétra, pp. 49-76.

KAMALOVA N. (2005) Voprosy migracii v Džizakskom viloâte [La question migratoire dans la région de Djizakh], in D.S. Azimova et E.V. Abdullaev Éds., Trudovaâ migraciâ: social'nye $i$ pravovye aspekty [Les migrations de travail : aspects sociaux et juridiques], Tachkent, pp. 29-34.

KOROBKOV A.V. and ZAIONCHKOVSKAIA Ž.A. (2004) The Changes in the Migration Patterns in the Post-Soviet States: The First Decade, Communist and Post-Communist Studies, 37, pp. 481-508.

ILKHAMOV A. (2006) Geographic Mobility of Uzbeks: The Emergence of Cross-national Communities vs. Nation-state Control, Paper for NBR Conference, Seattle, 23 p., http://www. nbr.org/Downloads/pdfs/PSA/Uzk_Conf06_Ilkhamov.pdf.

IVATOV I. (1994) Razvitie dehkanskogo rynk̄a v Uzbekistane [Le développement des marchés paysans en Ouzbékistan], Tachkent, Fan, 109 p.

Labour Migrants from Uzbekistan in the Southern Regions of Kazakhstan (2005) Almaty, IOM, $72 \mathrm{p}$.

LAITIN David (1998) Identity in Formation, the Russian-speaking Population in the Near Abroad, Ithaca-London, Cornell University Press, $417 \mathrm{p}$ 
LARUELLE Marlène (2007) Central Asian Labour Migrants in Russia: The "Diasporization" of the Central Asian States?, China and Eurasia Forum Quarterly, 5 (3), pp. 101-119.

LARUELLE Marlène (Éd.) (2010a) Dynamiques migratoires et changements sociétaux en Asie centrale, Paris, Pétra, $320 \mathrm{p}$.

LARUELLE Marlène (2010b) Le Kazakhstan, nouveau carrefour migratoire d'Asie centrale, in Marlène Laruelle Éd., Dynamiques migratoires et changements sociétaux en Asie centrale, Paris, Pétra, pp. 77-98.

MAKSAKOVA L.P. (1986) Migraciâ naseleniâ v Uzbekistane [Les migrations de population en Ouzbékistan], Tachkent, Uzbekistan, 208 p.

MAKSAKOVA L.P. (2001) Migraciâ naseleniâ: problemy regulirovaniâ [La régulation des migrations de population], Tachkent, Eldinur, $185 \mathrm{p}$.

MAKSAKOVA L.P. (2005) Trudovaâ migraciâ naseleniâ Uzbekistana: tendencii i regional'nye osobennosti [Les migrations de travail en Ouzbékistan : dynamiques et spécificités régionales], in D.S. Azimova et E.V. Abdullaev Éds., Trudovaâ migraciâ. social'nye i pravovye aspekty, Tachkent, pp. 6-19.

MAKSAKOVA L.P. (2008) Vnutrennaâ migraciâ naseleniâ Uzbekistana: sociologičeskie aspekty [Les migrations intérieures en Ouzbékistan : une approche sociologique], in E.V. Abdullaev Éd., Trudovaâ migraciâ v respublike Uzbekistan, Tachkent, UNDP, pp. 44-56.

MAKSAKOVA L.P. (2009) Uzbekistan v sisteme meždunarodnyh migracii [L'Ouzbékistan dans le système migratoire international], in Ž.A Zajonckovkaâ et G. S. Vitkovskaâ Éds., Postsovetskie transformacii: otraženie v migraciâh, Moscou, Adamant, pp. 323-349.

MASSOT Sophie (2009) Enjeux politiques et identitaires de la migration internationale des Ouzbeks vers trois pôles urbains (Moscou, Séoul, New York), Thèse de doctorat, Sciences Po Paris, 484 p.

Migration in Central Asia: Challenges and Prospects (2005), Almaty, Unesco, 202 p.

MULLÂDŽANOV I.R. et UBAJDULLAEVA R.A. (Éds.) (1988) Razvitie narodonaseleniâ $i$ problemy trudovyh resursov republik Srednej Azii [Croissance démographique et ressources laborieuses en Asie moyenne], Tachkent, Fan, 164 p.

Naselenie Uzbekistana: 15 let nezavisimogo razvitiâ [La population de l'Ouzbékistan : quinze ans de développement indépendant] (2007), Tachkent, Centr social'no-èkonomičeskih issledovanij, UNFPA, $271 \mathrm{p}$.

OLIMOVA S.K. et SADOVSKAÂ E.Û. (2005) Trudovaâ migraciâ v stranah Central'noj Azii, Rossijskoj Federacii, Afganistane i Pakistane [Les migrations de travail en Asie centrale, en Russie, en Afghanistan et au Pakistan], Almaty, EC, IOM, 146 p.

PATNAIK Ajay (1995) Agriculture and Rural Out-migration in Central Asia (1960-1991), EuropeAsia Studies, 47 (1), pp. 147-169.

RABALLAND Gaël (2005) L'Asie centrale ou la fatalité de l'enclavement, Paris, L'Harmattan, IFEAC, $355 \mathrm{p}$.

REEVES Madeleine (2010) Migrations, masculinité et transformation de l'espace social dans la vallée de Sokh, in Marlène Laruelle Éd., Dynamiques migratoires et changements sociétaux en Asie centrale, Paris, Pétra, pp. 217-245.

Rynok meždunarodnyh denežnyh perevodov $v$ Uzbekistane [Le marché des transferts d'argent internationaux en Ouzbékistan] (2007), Tachkent, Centr po soveršenstvovaniû antimonopol'noj politiki, $83 \mathrm{p}$.

SADOVSKAÂ E.Û. (2009) Kazahstan v central'noaziatskoj migracionnoj subsisteme [Le Kazakhstan dans le sous-système migratoire centre-asiatique], in Ž.A Zajonckovkaâ et G.S. Vitkovskaâ Éds., Postsovetskie transformacii: otraženie v migraciâh, Moscou, Adamant, pp. 279-322.

SAGERS Matthew J. and MARAFFA Thomas (1990) Soviet Air Passenger Transportation Network, The Geographical Review, 80 (3), pp. 266-278.

SAGERS Matthew J. and MARAFFA Thomas (1991) The Spatial Structure of Air Passenger Services for Kiev and Tashkent, Soviet Geography, 32 (5), pp. 314-326. 
TARASOVA N.V. (1985) Problema povyšeniâ migracionnoj aktivnosti naseleniâ [L'accroissement de l'activité migratoire], in Sovremennye problemy migracii [Les problèmes contemporains des migrations], Moscou, Mysl', 1985, pp. 47-63.

TAŠBAEVA T.H. et SAVUROV M.D. (1989) Novoe i tradicionnoe v bytu sels'koj sem'i Uzbekov [Nouveauté et tradition dans le mode de vie des familles rurales ouzbèkes], Tachkent, Fan, $162 \mathrm{p}$.

THOREZ Julien (2005) Flux et dynamiques spatiales en Asie centrale - Géographie de la transformation post-soviétique, Thèse de doctorat, Université Paris X-Nanterre, $570 \mathrm{p}$.

THOREZ Julien (2007a) Itinéraires du déracinement - L'essor des migrations de travail entre l'Asie centrale et la Russie, Espaces, populations et sociétés, 1, pp. 59-71.

THOREZ Julien (2007b) La construction territoriale de l'indépendance : réseaux et souveraineté en Asie centrale post-soviétique, Flux, 70, pp. 33-48.

THOREZ Julien (2008) Bazars et routes commerciales en Asie centrale. Transformation post-soviétique et «mondialisation par le bas », Revue Européenne des Migrations Internationales, 24 (3), pp. 167-189.

THOREZ Julien (2009) « Хорошо где нас нет »! L'émigration des « Russophones » d'Asie centrale, EchoGéo, 20 p., http://echogeo.revues.org/index10890.html.

TINGUY Anne de (2004) La grande migration. La Russie et les Russes depuis l'ouverture du rideau de fer, Paris, Plon, $662 \mathrm{p}$.

TOPILIN A.V. (1975) Territorial'noe pereraspredelenie trudovyh resursov SSSR [La redistribution territoriale de la main-d'œuvre en URSS], Moscou, Ekonomika, 1975, 159 p.

Trudovye migranty iz Uzbekistana v iužnyh regionah Respubliki Kazahstan [Les migrants de travail d'Ouzbékistan dans les régions méridionales du Kazakhstan] (2005), Almaty, MOM, 37 p.

ZAJONČKOVSKAÂ Ž.A. (1996) Istoričeskie korni migracionnoj situacii v Srednej Azii [Les racines historiques de la situation migratoire en Asie moyenne], in G.S. Vitkovskaâ Éd., Migraciâ russkoâzyčnogo naseleniâ iz Central'noj Azii: pričiny, posledsvtiâ, perspektivy [L'émigration des populations russophones d'Asie centrale : causes, conséquences, perspectives], Moscou, Carnegie, pp. 41-64.

ZAJONČKOVSKAÂ Ž.A (2008) Migracia naseleniâ iz stran Central'noj Azii [Les migrations de population depuis les pays d'Asie centrale], in E.V. Abdullaev Éd., Trudovaâ migraciâ v respublike Uzbekistan, Tashkent, UNDP, pp. 24-34.

ZAJONČKOVSKAẨ Ž.A., MKRČÂN N. et TÛRÛKANOVA E. (2009) Rossiâ pered vyzovami immigracii [La Russie face à l'appel de l'immigration] in Ž.A Zajonckovkaâ et G.S. Vitkovskaâ Éds., Postsovetskie transformacii: otraženie v migraciâh, Moscou, Adamant, pp. 9-62.

ZAJONČKOVSKAÂ Ž.A. et VITKOVSKAÂ G.S. (Éds.) (2009) Postsovetskie transformacii: otraženie v migraciâh [Les transformations post-soviétiques au miroir des migrations], Moscou, Adamant, $412 \mathrm{p}$.

ZÛZIN D.I (1983) Pričini nizkoj mobil'nosti korennogo naseleniâ respublik Srednej Azii [Les causes de la faible mobilité des populations autochtones d'Asie moyenne], Sociologičeskie issledovaniâ, 1, pp. 109-118. 


\title{
La mobilité des migrants d'Ouzbékistan : transports, frontières et circulation migratoire
}

\author{
Julien THOREZ
}

\begin{abstract}
Depuis la fin des années 1990, la territorialité des populations centre-asiatiques d'Ouzbékistan se transforme rapidement, suite à l'émergence de migrations de travail, saisonnières et temporaires, qui questionnent le modèle de développement suivi depuis l'indépendance. Cette mobilité inédite, devant laquelle les autorités ont adopté une attitude ambiguë, s'inscrit dans des dynamiques globales et dans des dynamiques post-coloniales : structuré par des liaisons aériennes, ferroviaires et routières, l'espace de circulation des migrants s'étend de l'Asie orientale à l'Amérique $\mathrm{du}$ Nord, mais les principales destinations des travailleurs ouzbékistanais, qui sont majoritairement des hommes, sont la Russie et, secondairement, le Kazakhstan. Instaurant de nouvelles formes de dépendances, ces flux massifs renvoient à la trajectoire originale, du Nord vers le Sud, poursuivie par l'Ouzbékistan.
\end{abstract}

\section{Uzbekistan Migrants Movement: Transportation, Borders and Migratory Circulation}

\author{
Julien THOREZ
}

Since the late 1990s, the territoriality of Central Asian populations of Uzbekistan is changing, due to the emergence of labour migrations. Facing this seasonal and temporary mobility, Uzbekistanis authorities adopted an ambiguous attitude, since the new territorial and social practices raise questions about the development model followed after independence. This unprecedented mobility is a part of global and post-colonial dynamics: the migratory space, which is structured by airline, train and bus networks, is stretching from East Asia to North America. Nevertheless, the main destinations of Uzbekistanis workers, who are mostly men, are Russia and, secondarily, Kazakhstan. Introducing new forms of dependency, these massive flows refer to the original trajectory pursued by Uzbekistan, from the "North" to the "South".

\section{La movilidad de los emigrantes de Uzbekistán: transportes, fronteras y circulación migratoria Julien THOREZ}

Desde el final de los años 1990, la territorialidad de las poblaciones centroasiáticas de Uzbekistán se transforma rápidamente dado a la emergencia de migraciones de trabajo, estacionales y temporales, que ponen en tela de juicio el modelo de desarrollo seguido desde le independencia. Esta movilidad inédita, ante la cual las autoridades han adoptado una actitud ambigua, entra en la marco de dinámicas globales y postcoloniales: estructurado por conexiones aéreas, ferroviarias y de carreteras, el espacio de circulación de los migrantes se extiende desde Asia oriental hasta América del norte, pero las principales destinaciones de los trabajadores uzbecos, que son hombres en su mayoría son, Rusia sobre todo y luego Kazajstán. Al instaurar nuevas formas de dependencias, esos flujos masivos remiten a la trayectoria original, del Norte hacia el Sur, seguida por Uzbekistán. 


\title{
Мобильность мигрантов из Узбекистана: транспорт, границы и миграционные потоки

\author{
Julien THOREZ
}

\begin{abstract}
География населения Узбекистана центрально-азиатского происхождения изменилась с конца 1990-х годов, после появления и роста трудовых миграций, в том числе сезонных и временных. Новые социальные и территориальные практики и явления вызывают вопрос о пост-советской модели развития. Эти новые потоки, отношение к которым у властей двусмысленное, вписываются в картину глобальных и пост-колониальных процессов. Пространство миграций жителей Узбекистана, в основном мужчин, простирается от Восточной Азии до Северной Америки, но большинство из них работает в России, а также в Казахстане, куда они ездят самолётом, поездом или автобусом. Трудовые миграции порождают новые виды зависимости и меняют положение Узбекистана в глобальном мире: с его прежней «северной» принадлежности на «южную».
\end{abstract}

